\title{
Targeted Individual Support for Ethnic Minority Preschoolers in the Silent Period in Learning Chinese
}

\author{
Shek Kam Tse \\ Faculty of Education, The University of Hong Kong, Hong Kong SAR, China \\ Heiken To \\ Faculty of Education, The University of Hong Kong, Hong Kong SAR, China \\ Pik Fong Tsui \\ Faculty of Education, The University of Hong Kong, Hong Kong SAR, China \\ Victor Laing \\ Faculty of Education, The University of Hong Kong, Hong Kong SAR, China \\ Lu Sai Lam \\ Faculty of Education, The University of Hong Kong, Hong Kong SAR, China \\ Mei Chi Kwok \\ Faculty of Education, The University of Hong Kong, Hong Kong SAR, China
}

\begin{abstract}
The silent period is most frequently used to describe the period of second language (L2) acquisition where the learner displays no obvious language output. In Hong Kong, ethnic minority (EM) preschoolers face challenges on home, school and community levels in learning Chinese as a second language, meaning that for those in the silent period, it may particularly difficult to begin speaking Chinese, leading to slower language development. A support service was established, targeting EM preschoolers in Hong Kong who are experiencing the silent period in learning Chinese as a second language. Volunteer teachers conduct individual, one-to-one training with these preschoolers at their homes or at community centers. This study aims to explore the approximate length of the silent period for EM preschoolers in learning Chinese as a second language, comparing the effect of receiving the support as opposed to none, and identify perceived effective practices in the targeted individual support, using a mixed methods approach. Analysis on speaking scores of the Language Progression Framework (LPF) revealed that the average silent period without support lasted for approximately two years, which can be shortened by half a year with the support service. A case study on a preschooler and a semi-structured focus group interview with volunteer teachers revealed perceived effective practices including interesting activities and teaching materials, opportunities for social interaction with peers, establishing rapport between teachers and their preschoolers, and a positive attitude from parents in supporting their children in learning Chinese. Implications for EM preschoolers learning Chinese, integration with the local community, teaching practices and policy making are discussed.
\end{abstract}

Index Terms — silent period, ecological systems theory, second language, Chinese learning, ethnic minority

\section{INTRODUCTION}

\section{A. The Role of Home Language Environment in Facilitating Second Language Learning in Children}

According to Bronfenbrenner's Ecological Systems Theory (1977), child development can be viewed from five concentric levels. The core is formed by the microsystem, and describes children's interactions with the immediate environment, such as that with parents. Microsystems gather to form mesosystems, which refer to interactions between secondary stakeholders and how they affect the children, such as parent-teacher relations. This has led to an appreciation of how home, school, community environments, and their interactions, together contribute to learning in children (Tse et al., 2020).

Translating the theory into the context of second language learning, it implies a need to not only consider how language is taught in schools, but also to consider how children may learn the language in home and community environments. In particular, this study aims to focus on children's home environment, encompassing the physical environment, as well as parents and their interactions with their children. Alawawda and Razi (2020), citing Asgari and Mustapha (2011), point out the importance of the home environment in second language learning, as it is an immediate 
place where children are exposed to the language. Arnold (2019) also identifies the importance of the language being spoken in a learner's living environment. Barton (2007) considers language learning to be facilitated by social interactions, saying that "literacy is a social activity and can best be described in terms of people's literacy practices which they draw upon in literacy events" (p. 35). Nutbrown, Hannon, and Morgan (2005) indicate four important strands of early literacy development, namely, environmental print, books, early writing and oral language, which they regard as fundamental literacy experiences that could be encountered by preschoolers. Additionally, Coyle and Gracia (2014) suggest that these resources used for exposure to second languages for children need to be able to engage children's attention and highlight the words to be learnt, such as in the form of songs.

\section{B. Silent Period}

The term silent period is most frequently used to describe the period of second language (L2) acquisition where the learner displays no obvious language output. Tabors (2008) conceptualized second language development into four stages - home language use, silent period, telegraphic and formulaic speech, and productive language. Other definitions of the silent period also exist, such as the absence of syntactic features in speech and the absence of novel or spontaneous speech (Roberts, 2014; Dulay, Burt, \& Krashen, 1982).

The silent period forms a normal part of the L2 developmental sequence (Paradis, 2007), and may last for six months or more (National Association of the Education of Young Children, 1995). Silent period is usually observed in early childhood, and its characteristics include refusal and reluctance to interact with others using the second language (Drury, 2013), although children may continue to use non-verbal means to communicate.

The potential explanations behind the silent period have been investigated in previous studies, and are mostly psychological, developmental, and social in nature. Goldenberg, Hicks and Lit (2013) state that it is a period where children are figuring out how to communicate, thus taking on the role as spectators (Brice, 2002; Tabors, 2008). Silence may also indicate a lack of confidence in using the language, with Drury (2013) noting that some children may rehearse the language privately until they gain enough confidence to use it in interactions with others. This confidence also depends on the child's perceived acceptance from the teacher (Tabors, 2008). Depending on learning styles, children may emerge from the silent period through different ways, with inner directed children more likely to use strategies such as self-rehearsal, whereas other-directed children are more likely to acquire the language through interactions with others (Iddings \& Jang, 2008; Bligh \& Drury, 2015). An extended silent period however, according to Gibbons (1985), may be a mark of psychological withdrawal and lack of comprehension.

The implications of the silent period extend to broader social aspects, such as policies that facilitate learning of second languages in communities. The California Department of Education (2009) emphasizes that children only display second language output when they are ready, which requires a combination of skill, comfort and motivation, and that premature expectations can be detrimental to the language learning process. Drury (2013) urged educators to understand the role of silence using a social-cultural perspective, not dissimilar to the Ecological Systems Theory, and to utilize preschoolers' funds of knowledge in helping their second language learning. Drury (2013) also recommended the use of bilingual staff in linking up schools and families to facilitate second language learning in children. Bligh and Drury (2015) further added that appropriate policies must be in place to ensure that integrated frameworks for second language learning exist for preschoolers living in places where the spoken language is not their mother tongue.

\section{Difficulties Faced by Ethnic Minority Preschoolers Learning Chinese in Hong Kong}

The percentage of ethnic minorities (EM) in Hong Kong has been on the rise for the past years, constituting to $3.6 \%$ of the whole population (Census and Statistics Department, 2017). The percentage of EM preschoolers, in particular, formed around $7-8 \%$ of preschoolers in Hong Kong (Hue, 2011). The local community predominantly uses written Chinese, which refers to spoken Cantonese and written traditional Chinese in this study. EM preschoolers do not speak Chinese as their mother tongue, which creates difficulties for integration into the local community (Tse et al., 2020; Equal Opportunity Commission, 2019). Unlike their first languages such as Urdu and Thai that are phonological in nature, spoken Cantonese is dependent on letter-sound mapping, and written Chinese is orthographical in nature, meaning that first language skills cannot be transferred when learning Chinese as a second language (Tse, Leung, Tsui, Chan, \& Kwok, 2021).

Obstacles in learning Chinese as a second language for EM preschoolers also exist on home, school, and community levels. On the home level, EM families are likely to congregate with communities of similar backgrounds, reducing exposure of their children with locals, and consequently having less opportunities to practice Chinese (Equal Opportunity Commission, 2019). Kan, Miller, Cheung and Brickman (2020) found a correlation between the amount of second language use in preschoolers and that of their parents in the home environment. Together with the fact that EM parents are unlikely to speak Chinese nor provide their children with a home environment rich in second language resources to facilitate their learning (Tsung \& Gao, 2012), means that opportunities to practice Chinese are further reduced, leading to slower Chinese language development compared to local preschoolers.

On the school level, local kindergartens in Hong Kong adopt integrated curricula, meaning that Chinese is not taught as a discrete subject, nor is there a specific curriculum for systematically teaching Chinese as a second language in kindergartens (Tse et al., 2020). Kindergarten teachers may also have limited understanding of the languages and cultures of EM families, hindering parent-teaching communication in supporting learning of children (Tse et al., 2020). 
Community support for learning Chinese is mostly provided by social service agencies (Center for Excellence in Social Welfare, 2012), while the local government also provides information packages (Education Bureau, 2020). On closer inspection, these services are mainly targeted at older EM students and EM parents, but not preschoolers. Also, Chinese language courses offered for parents do not specify whether they focus on helping parents learning Chinese, or if they also include elements of parent education to teach parents how to facilitate their children in learning Chinese. This may be a potential issue, as without appropriate facilitating skills and knowledge, better Chinese proficiency of EM parents does not necessarily translate into better Chinese proficiency of their children.

\section{THE CURRENT STUDY}

Limited research has been conducted on the silent period in learning Chinese as a second language, and possible interventions that can be done. This study is part of the "C-for-Chinese@JC" Project, initiated by The Hong Kong Jockey Club Charities Trust for helping EM preschoolers to learn Chinese as a second language. For the purpose of clarity, the study will refer to the most frequently used definition of the silent period, i.e. when the learner displays no obvious language output when learning a second language.

One support service targeted at preschoolers displaying characteristics of the silent period is the one-to-one mentorship program, where Chinese-speaking volunteer teachers are assigned to provide one-to-one individual support to the preschoolers, hence term "targeted individual support". The service is conducted at the home level, as opposed to the school or community levels, as relatively more resources already exist in the latter two levels, as compared to that provided for homes, and also due to the aforementioned significance of homes as immediate environments that influence second language learning. The services provided include lessons for additional language practice with the preschoolers at home, or for those not wishing for home visits, in community centers, where the children feel comfortable in interacting with the mentors. Individual follow up sessions are also provided, while group learning activities will be held as appropriate. The content of the support service included the building of preschoolers' Chinese mental lexicon and phrases in the areas of self, family, peers, community, as well as daily survival Chinese. The support service lasted for three years with sessions conducted weekly.

This study is divided into three parts. The first aims to address the research question: (i) what is the approximate length of the silent period in learning Chinese as a second language for EM preschoolers, with and without the targeted individual support? The second and third parts aim to address the research question: (ii) what are the perceived effective practices of the support service?

\section{METHOdOLOGY (I)}

This section aims to explore the approximate length of the silent period in learning Chinese as a second language for EM preschoolers, and compare the effect of targeted individual support.

\section{A. Participants}

The experimental group consisted of 69 EM preschoolers of the 2017-18 cohort (39 males, 30 females, mean age at K1 entry: 41.19 months), whereas the comparison group consisted of 43 EM preschoolers of the 2016-17 cohort (24 males, 17 females, 2 missing gender information; mean age at K1 entry: 39.67 months) from 20 local kindergartens (i.e., those without attending the one-to-one mentorship program). The ethnicity of the EM preschoolers for the two groups included Filipino, Indian, Indonesian, Nepalese, Pakistani, Vietnamese, Thai and others. Their home languages consisted of Tagalog, Hindi, Indonesian, Nepali, Urdu, Vietnamese, Thai and others.

\section{B. Instruments}

The Language Progression Framework (LPF), developed by Lam, Hui and Cheung (2018) assesses the listening, speaking and reading abilities of EM preschoolers. It has shown rigor and has been used in other studies (Lam et al., 2018; Tse et al., 2020). As it is a standardized test used by the local government, only authorized access to the question papers are allowed. This study utilized the speaking component of the LPF, which evaluates preschoolers' abilities in five areas: asking and answering questions, describing personal experiences, providing information, and expressing personal views and feelings. Only the speaking section and not the listening and reading sections was included, as the silent period mainly concerns. A raw score is converted into four levels $\left(0,1,2,3,3^{*}\right)$, with $3^{*}$ being the highest. Only the speaking, and not the listening and speaking components, was selected as the silent period concerns speaking ability. According to the scoring guide, level 0 refers to preschoolers remaining completely silent or being unable to demonstrate ability in all of the listed areas in speaking. Level 1 refers to use of mainly simple words, with level 2 being the use of mainly short phrases, level 3 being a mixture of sentences and some short phrases, and level $3^{*}$ using complete sentences. 


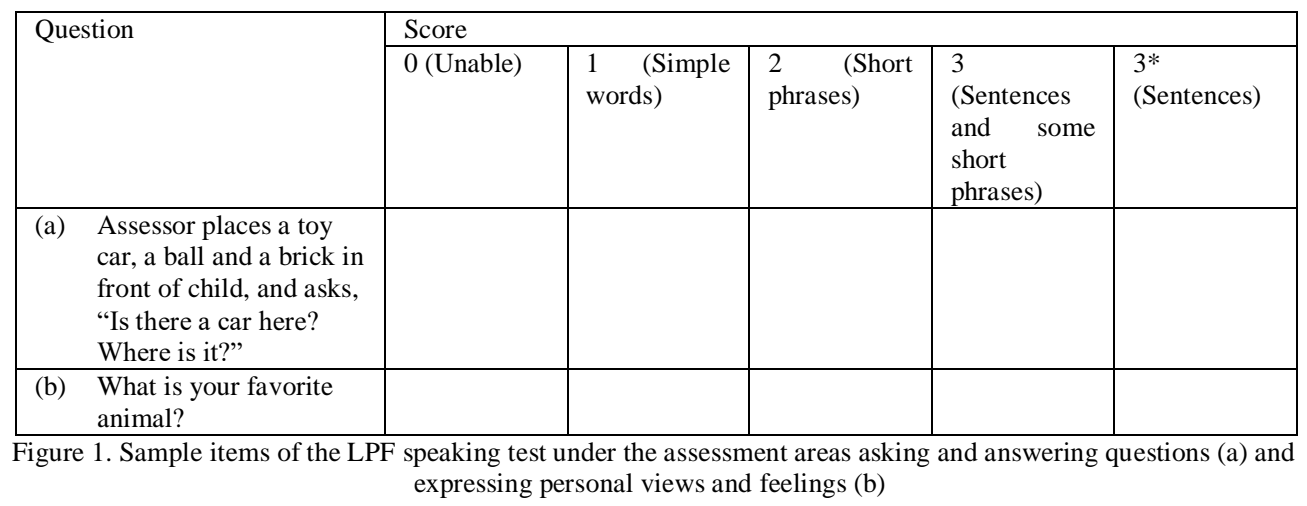

\section{Data Collection}

Data was collected from 2016-2020 at four time points for the two respective groups: at their K1 entry, at the end of their K1, K2 and K3 school years at kindergartens involved in the "C-for-Chinese@JC" Project. Consent was obtained from parents prior to data collection. The LPF test took approximately half an hour to complete.

\section{Data Analysis}

Cases with LPF speaking level 0 will be classified as being in the silent period in this study, as the scoring guide suggests that level 0 students remain completely silent or are unable to demonstrate ability in all of the listed areas in speaking. Reaching level 1 or above in the speaking test, as suggested by the scoring guide, suggests that the student is no longer in the silent period. To ensure the cases are indeed in the silent period, they are double checked with the class teachers of the preschoolers. A mixed ANOVA is then used to uncover the effects of support and time on the LPF speaking levels.

\section{RESUlts (I)}

A mixed ANOVA was conducted to examine the effects of one-to-one mentorship program support and time on the LPF speaking levels of EM preschoolers who were silent in the K1 pre-test, controlling for age, gender and ethnicity.

There was a main effect of support, $\mathrm{F}(1,107)=10.49, \mathrm{p}=0.002, \eta \mathrm{p} 2=0.09$. With preschoolers receiving the support showing higher LPF speaking levels $(M=0.99, n=69)$ when compared to those who received none $(M=0.68, n=43)$.

The assumption of sphericity was violated, therefore a Greenhouse-Geisser correction was applied. As expected, there was a main effect of time on LPF speaking levels of EM preschoolers, $F(3,206.58)=3.24, p=0.04, \eta p 2=0.29$, with each time-point showing a higher mean speaking level compared to the previous time-points $(\mathrm{K} 1 \mathrm{pre}-\mathrm{test}=0, \mathrm{~K} 1$ post-test $=0.61, \mathrm{~K} 2$-post-test $=1.05, \mathrm{~K} 3$ post-test $=1.68$ ).

There were no significant interaction effects between time and program support. Age, gender and ethnicity respectively with time also did not show any significant main and interaction effects.

From the graph below, it can be seen that the average EM preschooler receiving the support reaches level 1 in speaking (i.e. leaving the silent period) between the K1 post-test and K2 post-test, which is around half a year ahead of the average EM preschooler receiving no support. That is, the length of the silent period for EM preschoolers learning Chinese as a second language without support is around two years, whereas with targeted support, this reduces to a year and a half. Together with the statistically significant main effect of home program support mentioned above, it means that an improved quality of home support is able to shorten the silent period of EM preschoolers in learning Chinese. 


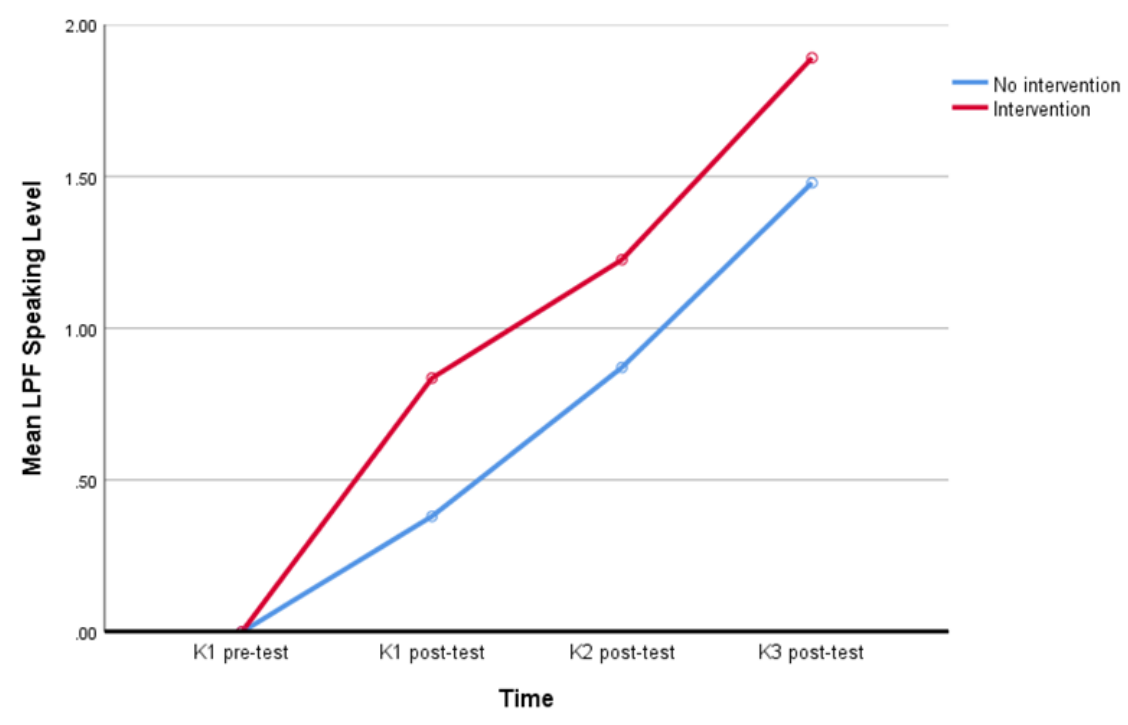

Figure 2. Mean speaking level of the two groups from K1 to K3.

\section{Methodology (II)}

This section aims to identify potential perceived effective practices in the program through a case study of an EM preschooler.

\section{A. Participants}

Rab (pseudonym) is a girl born in Pakistan who moved to Hong Kong when she was 1.5 years old. At the time of the study, she was 5 years old and was part of the 2017-18 cohort, studying in K2 in a local kindergarten. There are three other members in her family, including her parents and a younger brother. Punjabi is her mother language while Punjabi and Urdu are her parents' mother languages. Her father was then 26 years old and barely spoke Chinese, whereas her mother was 30 years old and did not speak Chinese at all.

Upon K1 entry, Rab showed characteristics of being in the silent period, with her LPF speaking level at 0 , indicating silence or unable to demonstrate any ability in the listed areas. Prior to attending the one-to-one mentorship sessions, teachers reported from their daily observations that Rab seemed inattentive in classes and gave minimal response to their instructions. For example, she usually shakes her head or answers with unintelligible sounds.

\section{B. Data Collection and Procedures}

The data for the one-to-one mentorship program was collected from 4th March to 25th March 2019. A total of six sessions were carried out by a Chinese-speaking volunteer teacher, with four sessions conducted at a local kindergarten and two at a learning center. The LPF data was collected from 2017-2020 at four time points: at Rab's K1 entry, and at the end of K1, K2 and K3 school years. An assessment form was collected from Rab's school teachers prior to entry to the mentorship program, inquiring about her learning progress. Consent was obtained from Rab's parents prior to data collection.

\section{Data Analysis}

Naturalistic observation was chosen as the data collection method as it provides a rounded picture of the sessions conducted. Also, a familiar environment, as suggested by Simons (2009), offers the opportunity to capture performances in genuine manners given that Rab was so young. The observation notes of each session were analyzed by a trained research assistant. The overall effectiveness, along with the good practices observed in the six sessions, was highlighted. The objectives of each session are as follows: 
TABLE 1.

SESSION OBJECTIVES OF ONE-TO-ONE MENTORSHIP PROGRAM

\begin{tabular}{|l|ll|}
\hline Session & & \\
\hline 1 & $\bullet$ & Understanding how to perform self-introduction in Chinese \\
& $\bullet$ & Recognizing the names of family members in Chinese \\
\hline 2 & $\bullet$ & Understanding the names of animals \\
& $\bullet$ & Understanding common daily phrases \\
\hline 3 & $\bullet$ & Understanding the names of colors \\
& $\bullet$ & Understanding common daily phrases \\
\hline 4 & $\bullet$ & Understanding the vocabulary of fruits \\
& $\bullet$ & Understanding common daily phrases \\
\hline 6 & $\bullet$ & To encourage preschoolers conducting conversations in Chinese with their peers \\
& $\bullet$ & Learning how to identify different colors in daily life \\
\hline
\end{tabular}

\section{RESUlTS (II)}

\section{A. Overall Improvement}

Overall, the Chinese speaking ability of Rab improved after the six sessions. She gave more reactions such as "yes" and "no", and in sessions 5 and 6 when another preschooler was paired with her for training in interacting with peers, Rab demonstrated increased frequency of speaking Chinese, with more diversified content. For example, when the other preschooler spoke in Urdu, which the teacher did not understand, Rab translated for the teacher. Also, her phrases were noticeably more complex, such as saying "no, she doesn't like it" and "you will be playing this later", compared to the individual sessions when she merely used "no". She also became more proactive in using Chinese over the six sessions, expressing enquiries to the teacher, such as using "what is it" or telling the teacher "I do not know". However, the teacher noted that she still tended to avoid saying more difficult words such as "purple". The volunteer teacher reflected that with appropriate teaching arrangements, EM preschoolers are also able to show interest in learning Chinese as a second language.

Although a direct causal relationship cannot be established, her LPF scores also provide some evidence that her speaking ability had improved. Prior to receiving the support at the end of K1, her LPF speaking level was at 1 , whereas at the end of $\mathrm{K} 2$ she improved to level 2, followed by level $3^{*}$ at the end of $\mathrm{K} 3$.

\section{B. Incorporating Interesting Activities and Teaching Materials to Motivate Learning}

Games were used in all five out of six observed sessions in various forms, and appeared to be the most successful practice of the mentorship program. For example, a sticker booklet was used in the first session to help Rab better retain vocabulary on family members. Rab showed a high level of interest in the game and was willing to speak Chinese to complete the game. In the third session, a game in which Rab needed to search for objects with different colors was used, and she was again motivated to answer in daily phrases. This behavior is in contrast to what the teachers reported in the intake form, as they reported Rab to be quite inattentive in class prior to entry into the program. During the sessions, Rab was only distracted when the games started to get boring. It is possible that games need to be varied and fresh in order to motivate learning. Below is an excerpt from the activity:

$\begin{array}{lll}\text { Teacher } & \text { (Places feathers with different colors around the room) } & \text { Okay you can start now. } \\ \text { Rab } & \text { (Finds a green feather and raises it with her hand) } & \\ \text { Teacher } & & \text { Say "found it!" } \\ \text { Rab } & \text { (Smiles) } & \text { Found it } \\ \text { Teacher } & \text { (Holds the feather in her hand) } & \text { What color is this? } \\ \text { Rab } & & \text { Green } \\ \text { Teacher } & & \text { A green feather! }\end{array}$

Books, pictures and word cards were used in four out of the six sessions in supporting the learning of Rab. In particular, they seemed to be helpful in introducing vocabulary to Rab. For example, a book was used to introduce vocabulary on family members in the first session. In the second session, word cards were used to introduce animal names to Rab. In the third session, picture cards were used to introduce names of fruits. In these three sessions, Rab seemed interested in the teaching materials, and achieved the objective of learning the vocabulary at a medium to good level.

\section{Social Interactions with Other EM Preschoolers}

In addition to individual games, social games were also used. Apart from the element of fun, being able to socialize can also be an incentive for preschoolers like Rab to practice speaking in Chinese. For example, in the fifth session, Rab played a game of passing on a message to another preschooler. Rab appeared to be willing to chat with the other preschooler in Chinese, fulfilling the objective of conducting conversations with their peers. In the sixth lesson, a game of role-play was used, where Rab played the role of a shopkeeper, whereas the other preschooler acted as the customer. 
Role-playing games provided Rab with opportunities to apply vocabulary learnt and use common phrases in a context similar to daily life.

\section{Paring with a Learning Partner with a Different Language Ability}

In the fifth and sixth sessions, Rab was paired with a K1 preschooler with a lower Chinese language ability, which was mutually beneficial for both. It is observed that Rab was able to act as a role model and was motivated to lead the other preschooler in using Chinese in their conversations. Not only was the other preschooler more motivated to speak in Chinese, but Rab was also able to practice her Chinese speaking skills in the process.

\section{E. Establishing Rapport}

It is noted that without first developing rapport in the first session between the volunteer teacher and Rab, the above good practices would not have been as effective. In the first session, the teacher allocated time at the beginning to introduce herself to Rab. Along with the aid of pictures, they talked about Rab's hobbies and age. Through this activity, the teacher was able to establish rapport from Rab.

\section{Methodology (III)}

This section aims to confirm and elaborate on the perceived effective practices from the perspectives of the volunteer teachers, through a focus group interview.

\section{A. Participants}

Five volunteer teachers (three males, two females) participating in the one-to-one mentorship program in the 2017-18 school year were included in the study.

\section{B. Data Collection and Procedures}

A semi-structured focus group interview was conducted with the volunteer teachers at a center in November 2017. Questions revolved around the practices that teachers considered to be successful in teaching Chinese as a second language to EM preschoolers. The interview lasted for approximately an hour. Consent was obtained prior to the interview.

\section{Data Analysis}

A thematic analysis was conducted on the focus group interview. The interview was first transcribed and crosschecked by two trained research assistants, then coded to generate themes, which were also cross-checked.

\section{RESULTS (III)}

\section{A. Incorporating Interesting Activities and Teaching Materials}

Four out of five volunteer teachers mentioned that it was important to design activities and made use of teaching materials that their EM preschoolers were interested in, so as to motivate them to speak Chinese. For example, when asked about what they considered to be helpful in managing their easiest and most difficult students, teacher B mentioned:

"I think it is important to play into the interests of the preschoolers. For example, my preschooler likes to do coloring, so we did some coloring on a coloring book, and I asked the preschooler to say 'I am coloring a flower'... simply sitting down and asking the preschooler to repeat after me is boring for the preschooler, having some activities may be more interesting for them." (Excerpt 1)

In another example, teacher $\mathrm{C}$ mentioned:

"I play into the interests of the students, for example, my preschooler likes to play hide and seek... instead of counting down in English, I suggested the preschooler to count in Chinese instead. That way the preschooler got to learn and practice saying Chinese numbers." (Excerpt 2)

This is similar to the findings in the second section, where games, pictures, books, and word cards were used to motivate the preschooler in learning and speaking Chinese.

\section{B. Social Interactions with Other EM Preschoolers}

Another finding that was similar to the second section was providing preschoolers with interactions with their peers. Teacher B mentioned that some interaction between EM preschoolers could perhaps motivate them to speak Chinese more often, perhaps pairing two teachers with their preschoolers. Teacher E mentioned:

"They don't usually speak Chinese when asked to do so out of context. There is no peer pressure. For example, social games could provide them with some context where they can speak Chinese in a way that more resembles daily conversations." (Excerpt 3)

\section{Establishing Rapport}

Similar to what was observed in the second section, Teacher $\mathrm{C}$ mentioned that his preschooler had genuine interest in learning Chinese, but needed a trusted person to bring out the interest. It was demonstrated when the preschooler 
actively asked teacher $\mathrm{C}$ questions such as "is that the word for horse?" and "is that Dou Dou's (character from storybook) home?".

\section{Support from Parents in Learning Chinese}

One successful practice that was not mentioned in the second section was the importance of support from EM preschoolers' parents in learning Chinese. For example, teacher B mentioned:

"For one of the preschoolers, the mother does not know how to speak Chinese, but nonetheless was enthusiastic in asking me if I could leave the teaching materials behind after class so she could use them to play with her child." (Excerpt 4)

Teacher D mentioned:

"Even though the mother does not speak Chinese herself, she marks down notes during the sessions, and even downloaded a Chinese application on her phone to learn Chinese herself. She now speaks Chinese better than her daughter." (Excerpt 5)

\section{E. Tailoring Teaching Goals According to Preschoolers' Language Ability}

Another practice that was not mentioned in the second section was tailoring of teaching goals according to preschoolers' Chinese language ability. Teacher E mentioned:

"I think it is important not to stick too much to the teaching plan, and not to force them to remember a certain amount of words per lesson, but simply allowing them to be able to listen and speak more often." (Excerpt 6)

\section{DISCUSSION}

This is one of the first studies conducted locally on EM preschoolers in the silent period learning Chinese as a second language. The first section of the results revealed that the average length of the silent period for EM preschoolers learning Chinese as a second language lasts for approximately two years, which is consistent with what previous literature suggests (National Association of the Education of Young Children, 1995). However, with targeted individual support, the average silent period becomes around a year and a half instead. This shows that with appropriate support, it is possible to shorten the silent period and allow EM preschoolers to start speaking Chinese sooner. In other words, EM preschoolers may benefit from an individualized curriculum tailored to meet their language learning needs in the silent period, which may not be readily available in classroom teaching at school.

The second and third sections of the results further explored the potential perceived effective practices behind the targeted individual support through a case study with an EM preschooler and also a focus group interview with volunteer teachers. In both sections, it was found that incorporating activities and teaching materials that were of interest to individual preschoolers motivated them to speak Chinese more often. These included a variety of games, books, pictures and word cards. In particular, elaborating on the previous claim by Coyle and Gracia (2014) that learning resources needed to capture preschoolers' attention the case study showed that to achieve this, games should aim to be fresh and avoid being repetitive. In addition, teachers also reported to play into the interests of students, often introducing Chinese words as the activities went, instead of having a predetermined group of vocabulary to teach.

Another common practice found in both sections was the opportunity for social interactions with peers. Interaction with peers seemed to provide more incentives for them to speak Chinese. In these instances, the preschoolers may be "other-directed" in their learning style, as suggested by existing literature (Iddings \& Jang, 2008; Bligh \& Drury, 2015), and are more likely to acquire the language through interactions with others. The fact that the current support is targeted at individuals does not mean that activities have to only involve a teacher and their preschooler. As one teacher suggested, two teachers could be paired with their respective preschoolers to allow more opportunities for interaction with peers, while still focusing on teaching their respective preschoolers during the process. Social games allow preschoolers to practice speaking Chinese in a way that more resembles daily conversations, as opposed to repeating Chinese words after the teacher, out of context. In turn, preschoolers are more likely to generalize their learning outside of the sessions.

The third common practice found in both sections two and three was establishing rapport between teachers and their preschoolers. With trust built between teacher and preschooler, preschoolers are more likely to express themselves and more willing to speak Chinese. This is consistent with previous literature stating that preschoolers needed confidence and perceived acceptance from the teacher in order to use the second language (Drury, 2013; Tabors, 2008). Having the comfort and security to use Chinese is also closely related to the additional finding of teachers tailoring teaching goals according to preschoolers' abilities. As suggested by the California Department of Education (2009), premature expectations can be detrimental to students' language development, as they need to be ready in terms of skill, comfort and motivation. Respecting the abilities and development of preschoolers and not stretching them too far gives a sense of comfort for them to explore the Chinese language.

The focus group interview with teachers revealed another important practice, which is the support from parents in learning Chinese. Positive attitudes and motivation towards supporting their children in learning a second language has been shown to be a factor in better linguistic performance (Alawawda \& Razi, 2020; Hosseinpur, Sherkatolabbasi, \& 
Yarahmadi, 2015). This was evident in parents taking down notes during the sessions, willing to use teaching materials outside of the sessions, and also downloading Chinese applications on their phone, as reported by the volunteer teachers.

A shortened silent period in learning Chinese as a second language may mean that EM preschoolers stand a better chance in acquiring the language earlier and experience better integration into the local society which uses Chinese as the predominant language (Tse et al., 2020; Equal Opportunity Commission, 2019).

With reference to Bronfenbrenner's Ecological Systems Theory (1977), the support service of this study attempted to link up community resources to EM families, and in doing so addressing the current difficulties and limitations faced by EM parents on home, school and community levels, namely EM families not being able to provide adequate exposure to the local language for their children, kindergartens not teaching Chinese as a discrete subject, and the lack of community resources targeted at EM preschoolers. In particular with regards to the home environment, which contributes to second language development as aforementioned, given that EM parents are unlikely to have a high proficiency in Chinese, nor interact regularly with their children in Chinese, the potential of the home environment in facilitating learning Chinese as a second language is not fulfilled. The significance of this targeted individual support is seen in volunteer teachers filling this role of EM parents, in that they make use of physical resources such as books, pictures and games to interact and socialize with EM children in Chinese at their homes. As for the perceived effective practices identified, existing literature mostly refers to these practices in the context of school settings, but have rarely explored how they can also be implemented in home settings. It can be said that the combination of learning resources and social interactions, used in conjunction with the perceived effective practices at the home level, together created a rich second language learning environment for EM preschoolers, which enabled their breakthrough of the silent period. While such a support service can help EM preschoolers in the short run, for their long-term Chinese language development, one should look into a service that can be conducted in parallel, in building the capacity of EM parents to create a home environment to facilitate language learning, such as improving their own Chinese proficiencies, and teaching them how to use Chinese language resources, as it is practically infeasible for volunteer teachers to remain with the preschoolers well into their primary and secondary school years.

As Bligh and Drury (2015) stated, appropriate policies in integrated frameworks for second language learning should be provided for students living in places where the spoken language is not their mother tongue. With the initial success of the targeted individual support in mind, from a policy perspective, it should be explored how such services could be refined and established in the long run, such that more EM preschoolers can be benefited. For example, referral schemes and programs could be set up in community agencies for preschoolers in need to join. Community agencies and kindergartens could cooperate so that both teachers at the kindergartens and the volunteer teachers of the services could be informed about the learning progress of the preschooler. In turn, their teaching goals could then be modified to better suit the needs of the preschooler. Another example would be to introduce some form of teacher training for the volunteer teachers so that they will be more sensitized not only to how to teach EM preschoolers, but also to understand their cultural backgrounds, traditions and practices in order to better teach and communicate with them and their families in a culturally responsive manner, as mentioned by Tse et al. (2020).

In conclusion, this is the first local study exploring the effects of targeted individual support on the silent period of EM preschoolers learning Chinese as a second language. Preschoolers receiving support were found to perform better than those who did not. Upon further examination, interesting activities and teaching materials, opportunities for social interaction with peers, establishing rapport between teachers and their preschoolers, and a positive attitude from parents in supporting their children in learning Chinese, were found to be practices contributing to the observed effect of the support service. As the current study is one of the firsts, the effectiveness of the targeted individual support remains to be seen on a larger scale in future studies. Future studies could also delve deeper into the perceived effective practices, such as how to bring about positive parent attitudes in supporting their children in learning Chinese as a second language. Also, studies could explore on ways to sustain the breakthrough of the silent period in the long-term.

\section{DiSCLOSURE STATEMENT}

No potential conflict of interest was reported by the authors.

\section{ACKNOWLEDGMENTS}

This work and the “C-for Chinese@ JC” project were supported by The Hong Kong Jockey Club Charities Trust.

\section{REFERENCES}

[1] Arnold, C. (2019). How action schemas are reflected in young children's emerging language. Early Child Development and Care, 189.12, 1992-2004.

[2] Asgari, A. \& G. B. Mustapha (2011). The influence of informal language learning environment (parents and home environment) on the vocabulary learning strategies. English Language and Literature Studies 1.1, 7. doi: 10.5539/ells.v1n1p7

[3] Barton, D. (2007). Literacy: An introduction to the ecology of written language (2nd ed.). London: Blackwell.

[4] Bligh, C. \& R. Drury (2015). Perspectives on the "Silent Period" for emergent bilinguals in England. Journal of Research in Childhood Education 29.2, 259-274. doi: 10.1080/02568543.2015.1009589. 
[5] Brice, A. E. (2002). The Hispanic child: Speech, language, culture and education. Boston: Allyn and Bacon.

[6] Bronfenbrenner, U. (1977). Toward an experimental ecology of human development. American psychologist 32.7, 513.

[7] California Department of Education (2009). English learners: Principles and practices to, promote language, literacy, and learning (2nd edn.). Sacramento, CA: Author.

[8] Census and Statistics Department, HKSAR. (2017). 2016 Population by-census - Thematic report: Ethnic minorities. Hong Kong: Census and Statistics Department. https://www.statistics.gov.hk/pub/B11201002016XXXXB0100.pdf (accessed 18/1/2021).

[9] Center for Excellence in Social Welfare. (2012). List of ethnic minorities service providers. http://c4e.hkcss.org.hk/eng/serviceprovision.php?n=6\&c=261 (accessed 18/1/2021).

[10] Coyle, Y. \& Gracia, R. G. (2014). Using songs to enhance L2 vocabulary acquisition in preschool children. ELT Journal 68.3, 276-285.

[11] Dulay, H. C., M. K. Burt \& S. D. Krashen. (1982). Language two. New York, NY: Oxford, University Press.

[12] Drury. (2013). How silent is the "Silent Period" for young bilinguals in early years settings in England?, European Early Childhood Education Research Journal 21.3, 380-391. doi: 10.1080/1350293X.2013.814362.

[13] Education Bureau. (2020). Non-Chinese speaking parent information package: Your guide to education in Hong Kong. https://www.edb.gov.hk/en/student-parents/ncs-students/support-to-student-and-parents/ncs-parent-information-package.html (accessed 18/1/2021).

[14] Equal Opportunities Commission, EOC. (2019). Closing the gap: Report of the working group on education for ethnic minorities. Hong Kong: Hong Kong Equal Opportunities Commission. https://www.eoc.org.hk/s/ClosingtheGap/Closing_the_Gap_Report.pdf (accessed 19/1/2021).

[15] Goldenberg, C., J. Hicks \& I. Lit. (2013). Dual language learners: Effective instruction in early childhood. American Educator $37,26-29$.

[16] Gibbons, J. (1985). The silent period: An examination. Language Learning 35, 255-267.

[17] Hosseinpur, V., M. Sherkatolabbasi \& M. Yarahmadi. (2015). The impact of parents' involvement in and attitude toward their children's foreign language programs for learning English. International Journal of Applied Linguistics \& English Literature $4.4,175-185$.

[18] Hue, M. T. (2011). Building up a culturally responsive school: Cross-cultural experience of ethnic minority students in Hong Kong schools. In J. Phillion, M. T. Hue \& Y. Wang (eds.), Minority students in far east Asia: Government policies, school practices and teacher responses. New York: Routledge, 141-154.

[19] Iddings, A. C. D. \& E. Jang. (2008). The mediational role of classroom practices during the silent period: A new-immigrant student learning the English language in a mainstream classroom. TESOL Quarterly 42.4, 567-590.

[20] Kan, P., Miller, A., Cheung, S., \& Brickman, A. (2020). The distributed L1 and L2 language-learning environments of duallanguage learners across home and school settings. Language, Speech \& Hearing Services in Schools 51.4, 1007-1023.

[21] Nutbrown, C., Hannon, P., \& Morgan, A. (2005). Early literacy work with families: Policy, practice and research. GB: Sage Publications Ltd.

[22] Paradis, J. (2007). Second language acquisition in childhood. In E. Hoff \& M. Shatz (eds.), Blackwell handbook of language development. Malden, MA: Blackwell, 387-405.

[23] Roberts, T. (2014). Not so silent after all: Examination and analysis of the silent stage in childhood second language acquis ition. Early Childhood Research Quarterly 29, 22-40.

[24] Tabors, P. O. (2008). One child, two languages: A guide for preschool educators of children, learning English as a second language (2nd edn.). Baltimore, MD: Paul H. Brookes Publishing.

[25] Tse, S. K., To, H., Pang, E. Y. W., Tsui, P. F., Lam, L. S., Laing V., \& Wu, K. (2020). Using the home-school-community model to enhance the Chinese language proficiency of non-Chinese speaking children. Creative Education 11, 2069-2095.

[26] Tse, S. K., Leung, C. Y., Tsui, P. K., Chan, K. Y., \& Kwok, M. C. (2021). A longitudinal investigation into the Chinese language development of non-Chinese speaking preschoolers in Hong Kong. Journal of Language Teaching and Research 12.1, 183.

[27] Tsung, L., \& F. Gao. (2012). What accounts for the underachievement of south Asians in Hong Kong? The voices of Pakistani and Nepalese parents. Educational Research 54, 51-63.

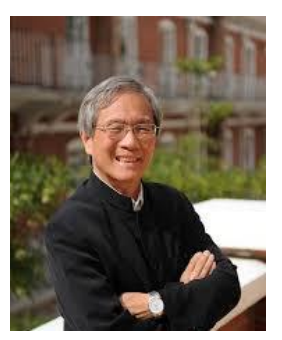

Shek Kam Tse is a professor at the Centre for Advancement of Chinese Language Education and Research (CACLER), Faculty of Education, The University of Hong Kong. His research interests include: (1) teaching Chinese as a second language; (2) the influence of support on early literacy development; and (3) effective Chinese language pedagogy for different stages of education.

Heiken To is a research associate at the Centre for Advancement of Chinese Language Education and Research (CACLER), Faculty of Education, The University of Hong Kong. 
Pik Fong Tsui is a senior research assistant at the Centre for Advancement of Chinese Language Education and Research (CACLER), Faculty of Education, The University of Hong Kong.

Victor Laing is a research assistant at the Centre for Advancement of Chinese Language Education and Research (CACLER), Faculty of Education, The University of Hong Kong.

Lu Sai Lam is a deputy project manager at the Centre for Advancement of Chinese Language Education and Research (CACLER), Faculty of Education, The University of Hong Kong.

Mei Chi Kwok is an assistant lecturer at the Centre for Advancement of Chinese Language Education and Research (CACLER), Faculty of Education, The University of Hong Kong. 